\title{
EDITORIAL
}

\section{Evidencia en atención primaria: es necesario?}

Los médicos de atención primaria, cualquiera sea nuestra especialidad, tenemos la responsabilidad de mantenernos actualizados con los avances científicos y los aportes que la literatura médica brinda dia a día. Anteriormente, el limitado conocimiento sobre la biología humana y la escasez de estudios de investigación clínica determinaban que estos avances científicos fueran publicados con mucha menor frecuencia y, por lo tanto, "estar al día" era considerablemente más fácil. En los últimos 40 años, el progreso en el conocimiento de las ciencias básicas hizo posible comprender muchos fenómenos biológicos. Esto además fue acompañado por un desarrollo muy importante de los métodos epidemiológicos que determinaron el punto de partida de los estudios clínicos y su directa aplicación en el manejo de la población en general y los pacientes en particular. Se comenzaron a conocer factores asociados al desarrollo de ciertas enfermedades, a medir la ocurrencia de los eventos, a diseñar tratamientos y a evaluar los resultados. El número de publicaciones se multiplicó a tal punto que hoy existen cientos si sumamos todo el espectro de las especialidades médicas.

Por otra parte, la permanente presión que se ejerce sobre los investigadores de los centros académicos para publicar más y así garantizar su promoción y la obtención de los fondos que financian los distintos proyectos de investigación lleva frecuentemente a la publicación de un sinnúmero de estudios de calidad objetable desde distintos puntos de vista.

Cuanto más escasos son los recursos de un país, mayor es la necesidad de planificar en base a prioridades que deben indefectiblemente basarse en la evidencia más sólida. Durante nuestra formación profesional no recibimos entrenamiento formal sobre metodología de investigación ni sobre estrategias de revisión crítica de la literatura. También es verdad que en la mayoría de los casos tampoco existe el tiempo necesario para buscar información (o la infraestructura necesaria para obtenerla) que dé respuesta a la infinidad de preguntas que surgen en la práctica clínica diaria sobre los problemas particulares que enfrentamos cuando estamos con un paciente. Esto es muy importante ya que, en un gran número de casos, seguimos basando nuestras conductas y decisiones médicas en conocimientos desactualizados incorporados durante nuestra formación o en la sobreinterpretación de experiencias sobre pacientes individuales que pueden carecer de la necesaria objetividad y representatividad.

Las fuentes a las que podemos recurrir para las búsquedas bibliográficas, grandes bases de datos como MEDLINE, EMBASE, COCHRANE o sitios de INTERNET o las publicaciones dedicadas a la revisión periódica de la literatura tales como el ACP Journal Club (aparece cada 2 meses con el Annals of Internal Medicine), el Journal Watch o el recientemente aparecido Evidence Based Medicine, tienen todavía un acceso limitado, ya sea por falta de infraestructura o por barreras idiomáticas. Además, existe un constante bombardeo de información médica y para cualquier médico de hoy es absolutamente im- 
posible mantenerse al día con la que aparece periódicamente (alrededor de 20 artículos diarios, 365 días al año según lo calculado por Sackett ). Por este motivo es que necesitamos establecer prioridades y adquirir nociones básicas de revisión de la literatura para priorizar qué vamos a leer en el escaso tiempo que tenemos y cuál es la mejor evidencia para responder a nuestras preguntas.

La Medicina Basada en la Evidencia es esencialmente una estrategia de aprendizaje que intenta llenar la brecha existente entre la investigación y la práctica clínica corriente, brindando los elementos necesarios para poder interpretar críticamente la literatura y asegurar una buena calidad de atención médica. David L. Sackett, uno de los "fundadores" de esta disciplina que aplica directamente los conceptos de la epidemiología clínica a la práctica diaria, la describe como el proceso de convertir los problemas clínicos en preguntas, en base a las cuales se busca la información, se evalúa el grado de evidencia que provee y se la utiliza como guía para una toma de decisiones adecuada.

Hasta hoy no existía ninguna publicación en castellano dedicada a la selección y revisión crítica de estudios relevantes en el campo de la atención primaria en el contexto de nuestra práctica.

Evidencia en Atención Primaria estará constituida por las siguientes secciones:

1) Cuerpo principal: presentación de estudios originales rigurosamente seleccionados que serán resumidos y comentados por médicos entrenados en las áreas de metodología, epidemiología, bioestadística y efectividad clínica.
2) Glosario: Définiciones de términos epidemiológicos usados en los artículos y comentarios con el objetivo de aclarar dudas y familiarizarse con el vocabulario.

3) Correo de Lectores: La intención es crear un ámbito de comunicación donde no solo se discutan temas clínicos o epidemiológicos sino también podamos intercambiar sugerencias e ideas.

4) Periódicamente se incorporarán revisiones de temas clínicos relevantes en atención primaria o temas de Epidemiología clínica y metodología de la investigación.

Como médicos de atención primaria tenemos la responsabilidad de interpretar críticamente la literatura médica y evaluar la evidencia disponible antes de tomar posición con respecto a una conducta determinada. Sólo de esta forma podremos informar y aconsejar correctamente a nuestros pacientes y garantizar una atención de alta calidad.

Creemos que Evidencia, al utilizar criterios explícitos de interpretación crítica de la literatura para evaluar la validez y relevancia de su contenido, ofrecerá una fuente confiable y accesible de actualización y educación médica continua.

\section{Fernando Rubinstein}

\section{Referencias:}

Davidoff, F. Evidence Based Medicine. BMJ: 1995: 310: 1085-1086

Rosemberg, W. Donald A. Evidence Based Medicine: an approach to clinical problem solving BMJ: 1995: 310: 1122-1126.

Dawes M. On the need for evidence based general and family practice, EBM: 1996, vol 1, Number 3, 68-69 